\title{
Optimisation of Continuous and Pulsed Cooling in Injection Moulding Processes
}

\author{
A G Smith, L C Wrobel \\ School of Engineering and Design, Brunel University, Uxbridge UB8 3PH, UK
}

B A McCalla, P S Allan

Wolfson Centre for Materials Processing, Brunel University, Uxbridge UB8 3PH, UK

P R Hornsby

School of Mechanical and Aerospace Engineering, Queen's University Belfast, Belfast BT9 5AH, UK

\begin{abstract}
The concept of pulsed cooling in injection moulding involves cycling the flow of coolant in order that cooling only takes place as and when it is required, as opposed to continuous cooling, where the coolant in run through the channels throughout the entire process. It is claimed that using the pulsed cooling method, with reduced temperature coolants, may reduce cycle times and overall energy consumption for the injection moulding process, when compared with continuous cooling. It is also suggested that this is not at the expense of component integrity since common defects such as warpage, which could come about due to non-uniform cooling of the component, or impedance of flow of the polymer into the mould cavity during injection, do not normally appear.
\end{abstract}

The study described in this paper uses a previously validated numerical model in order to optimise the cooling phase of the injection moulding process, for both continuous and pulsed cooling, in order to assess the advantages and disadvantages of each method, with respect to cycle times. In addition, the optimisations were carried out with a view to improving cycle times experimentally, taking into consideration the findings of the study. 


\section{Introduction}

The cooling phase of the injection moulding process accounts for up to $75 \%$ of the overall cycle time. It therefore follows that a reduction in cooling time will in turn reduce overall cycle time and hence, enable a greater number of components to be produced in the same time frame.

There are three different types of mould tool which are relevant when producing injection-moulded components. These three situations are moulds that run at or below ambient temperature, moulds that run slightly above ambient temperature and moulds that run at a temperature significantly higher than ambient temperature [1]. The running temperature of the mould tool is defined by the polymer being used and the injection temperatures and pressures in operation. This work concentrates on a tool that ran at a temperature slightly above ambient temperature, whereby background heating is not required.

The optimum thermal control of a mould surface would enable maintenance of the required mould surface temperature (tool running temperature) for the injection of the molten polymer and then be able to efficiently extract the heat from the mould, whilst ensuring that the surface temperature returned to the tool running temperature prior to the injection of a consecutive shot. The main elements for an efficient thermal control of the tool are: the design and location of the heating/cooling channels, the flow rate and temperature of the heating/cooling medium, and the physical/thermal properties of the tool and polymer materials. The work described here is concerned with the flow rate and temperature control of the heating/cooling medium.

The conventional cooling method used is continuous cooling. This approach involves a constant coolant flow through the channels of the tool, throughout the complete process. Using this method dictates that a coolant temperature at, or close to, the tool running temperature must be used. This ensures that the entire surface of the tool cavity is at, or above, the tool running temperature prior to the injection of each shot, minimising impedance of flow of the polymer into the mould cavity. 
Another cooling method is pulsed cooling. Pulsed cooling aims to control the surface temperature of the tool cavity by using controlled coolant pulses through the channels, in response to temperature changes monitored by sensors located in the body of the mould tool. This approach enables reduced temperature coolants to be used as cooling only takes places once temperatures at the sensors rise above the desired setpoint temperature. Coolant flow is stopped once the temperature at the sensor drops below the set-point temperature and hence, enough heat has been removed from the tool. Therefore, cooling only takes place when it is required. Ideally, a coolant pulse is initiated once per cycle. Potential benefits of pulsed cooling include increased output, improved product quality, improved cycle time, reduced scrap, reduced power usage, reduced down time, reduced maintenance, versatile and easy to use systems, long life expectancy of control systems, floor space savings and rapid pay back $[2,3]$.

Independent studies to validate some of the above claims have been done using experimental techniques. These studies have all concluded that there are benefits to employing pulsed cooling, as discussed below:

Pulsed cooling has been shown to offer $20 \%$ reductions in cycle times, when compared with continuous cooling [4]. This conclusion was based on results obtained for a particular tool geometry, using various different coolant temperatures and tool temperatures, with polypropylene as the polymer. Results were generated for both continuous and pulsed cooling at four different mould tool temperatures (tool running temperatures), $20^{\circ} \mathrm{C}, 25^{\circ} \mathrm{C}, 35^{\circ} \mathrm{C}$ and $50^{\circ} \mathrm{C}$. The results for this polymer, at each running temperature, showed improved cycle times when the pulsed cooling system was employed. As part of this study, the National Physical Laboratory in the UK carried out multiple tests on parts produced using both cooling methods. They were unable to find any noticeable differences between the polymer or part properties using either method.

A further study was conducted to look at the ability to regulate the tool temperature at various locations throughout the tool, for the two cooling methods [5]. The original thermocouples were located in the main body of the fixed and moving halves of the tool and represented the zone temperatures for the tool. Probes were located close to the moulding surface, in order to give a more accurate representation of the cavity 
surface temperature. Data was collected at four probe locations in order to monitor the temperatures throughout both zones. The results showed that pulsed cooling enabled far greater control of the temperature of the cavity surface, compared to conventional cooling. In addition, it required fewer cycles before equilibrium was reached, whereby the temperature profiles at the start of consecutive cycles were the same throughout the tool.

This study reinforced the result that using pulsed cooling does not diminish the integrity of injection-moulded components, when compared with continuous cooling. The results obtained showed that when pulsed cooling was used, a greater consistency of component size and weight was achieved. This was due to pulsed cooling enabling far greater control over the temperature at the surface of the tool. Monitoring and regulating the surface temperature rather than the temperature within the body of the tool is far more useful, as the polymer only comes into contact with the cavity surface. Other important benefits of pulsed cooling relate to the reduction in energy consumption during moulding and a cost benefit arising from reductions in cycle time [6].

A detailed study was conducted in order to look at the energy consumption during the production of 10,000 identical components. Component warpage was used as the experimental control and was regulated by using a coolant temperature for pulsed cooling, which gave identical cycle times to those obtained using continuous cooling. By constraining cooling times in this way, measured component distortion was kept within acceptable limits. The work concluded that the energy savings were substantial when pulsed cooling was used. Although quantitative values were not given, the work also concluded that further energy saving were made when colder cooling media were used. This was carried out separately from the study, as component integrity was used as the control for this experiment, which was achieved by using a coolant at higher temperature.

Computational Fluid Dynamics (CFD) offers an alternative approach for analysing pulsed cooling. Commercial CFD codes incorporate solvers for both fluid flow and heat transfer problems and hence, are ideal for analysing the cooling phase of the injection moulding process. By simulating continuous and pulsed cooling, 
comparisons can be made and, in addition, procedures can be followed in order to optimise both cooling processes, without the expense of modifying mould tools. Numerical models can also provide additional information that cannot be obtained experimentally, such as surface temperatures and temperature contour fields throughout the body of the tool.

The objective of the work presented in this paper is to optimise the cooling phase of the injection moulding process, using a numerical model, for both continuous and pulsed cooling, in order to assess the advantages and disadvantages of each method, with respect to cycle times. The model used was previously validated by comparing the results obtained for continuous cooling with those obtained experimentally [7].

\section{Numerical Model Setup for Optimisation}

Figure 1 shows a pictorial representation of the assembled geometry used as the flow domain. The model geometry was identical to the actual tool but only half the tool was modelled, with a symmetry plane running through the centre of the fixed, moving and insert zones.

Figures 2 to 4 show pictorial representations of the final mesh used in the simulations, which was based on the commercial CFD package FLUENT version 6.0. Figure 2 shows an isometric view of the complete mesh, figure 3 shows a section of the surface mesh on the part and the channels and figure 4 shows the mesh from a plan view in order to highlight the areas where the mesh was most refined. The final mesh contains around 2,000,000 elements. 


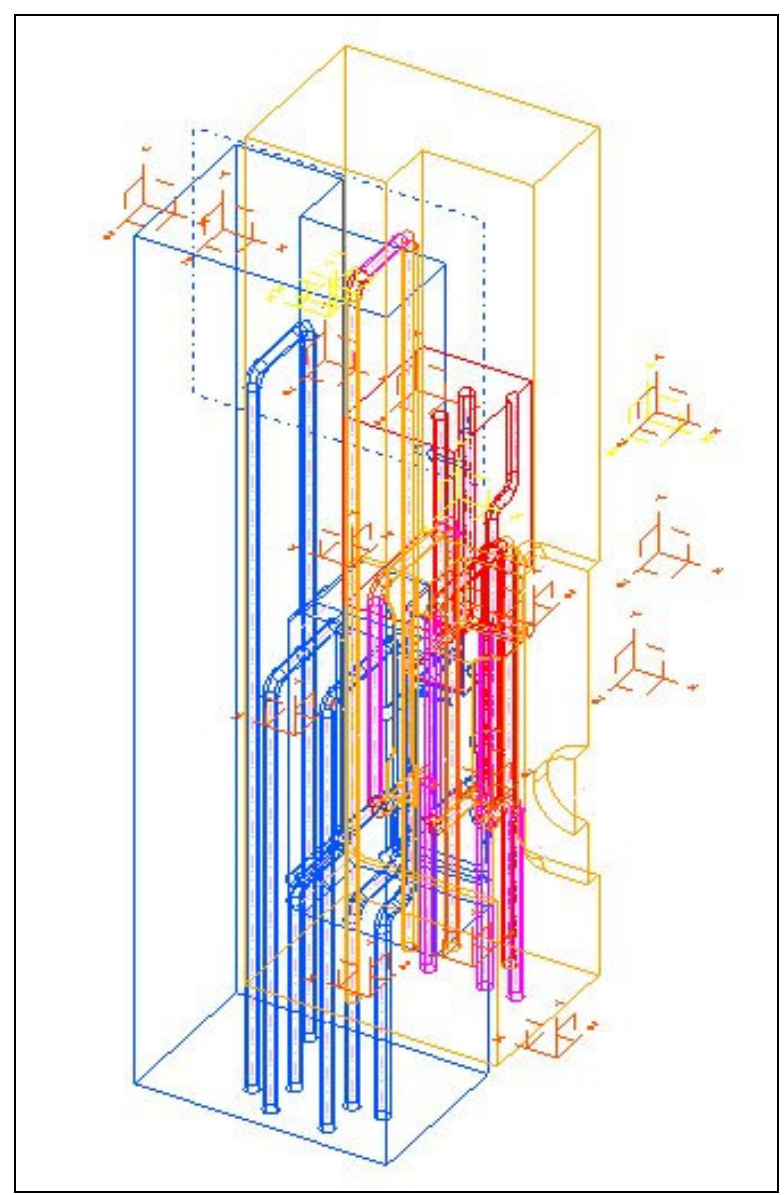

Figure 1: Pictorial Representation of the Final Geometry

In summary, a three-dimensional, segregated, unsteady, $1^{\text {st }}$ order implicit solver was used. Temperature-dependent thermal properties, implemented in FLUENT as piecewise linear functions, were assigned for the polymer (homopolymer polypropylene SM6100) [8], while constant thermal properties were used for the tool and coolant. All symmetry faces were assigned a heat flux of zero by default, and all other external faces of the tool had a convective heat transfer coefficient of $15 \mathrm{~W} / \mathrm{m}^{2} \mathrm{~K}$ assigned to them [9], with a free stream temperature of $27^{\circ} \mathrm{C}$. The k-epsilon viscous model was used to define the turbulent flow in the channels, with a turbulence intensity of $6.6 \%$ and a length scale of $0.7 \mathrm{~mm}$ defined, calculated from equations in the FLUENT 6.0 user guide [10]. The coolant velocity was set at $12 \mathrm{~m} / \mathrm{s}$. 


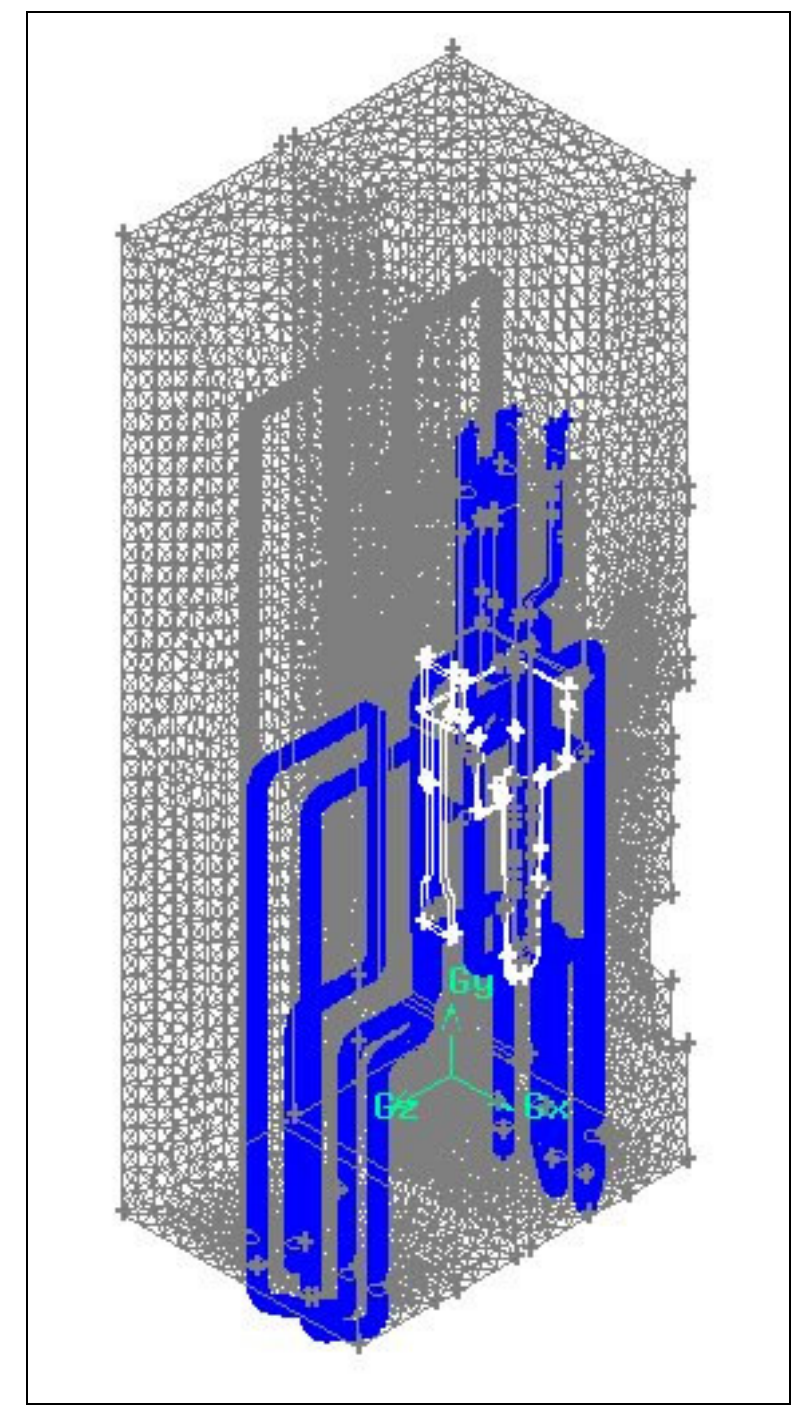

Figure 2: Isometric View of Final Mesh

Initially, the tool was set at the running temperature of $50^{\circ} \mathrm{C}$ and the component was set at the polymer injection temperature of $220^{\circ} \mathrm{C}$. Once the value at the primary sensor reached the ejection temperature of $60^{\circ} \mathrm{C}$, a further 10 seconds was allowed to pass prior to the re-patching of the part at $220^{\circ} \mathrm{C}$. This delay accounted for the time taken to open the tool, eject the part, close the tool and re-inject the polymer into the cavity. This time span was kept constant throughout all simulations even though this was not the case for some of the experimental work, because the time taken for the machine to prime was not one of the factors under investigation. Experimentally, this time ranged between 10 and 20 seconds. 


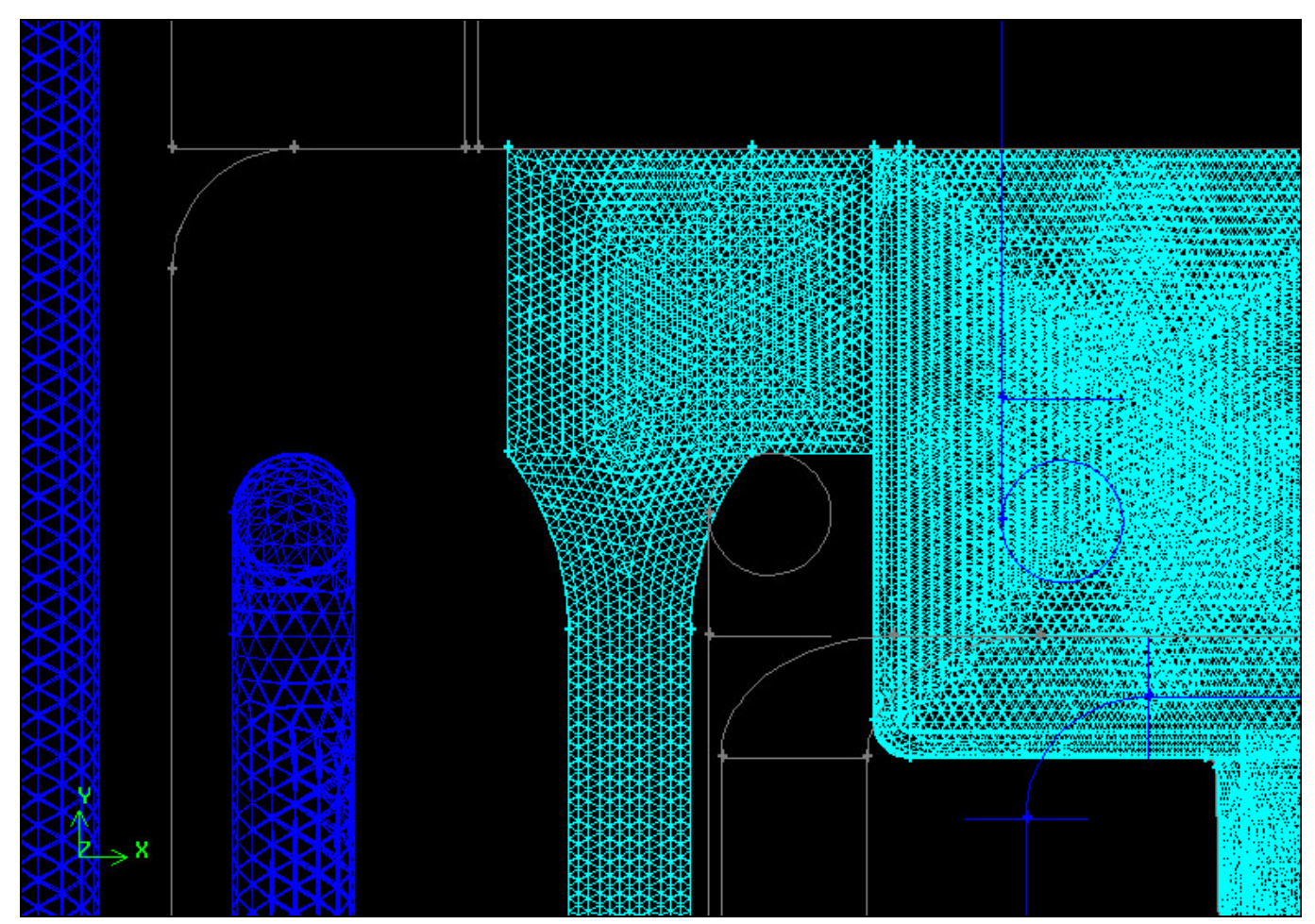

Figure 3: Surface Mesh on Component and Channel Surfaces

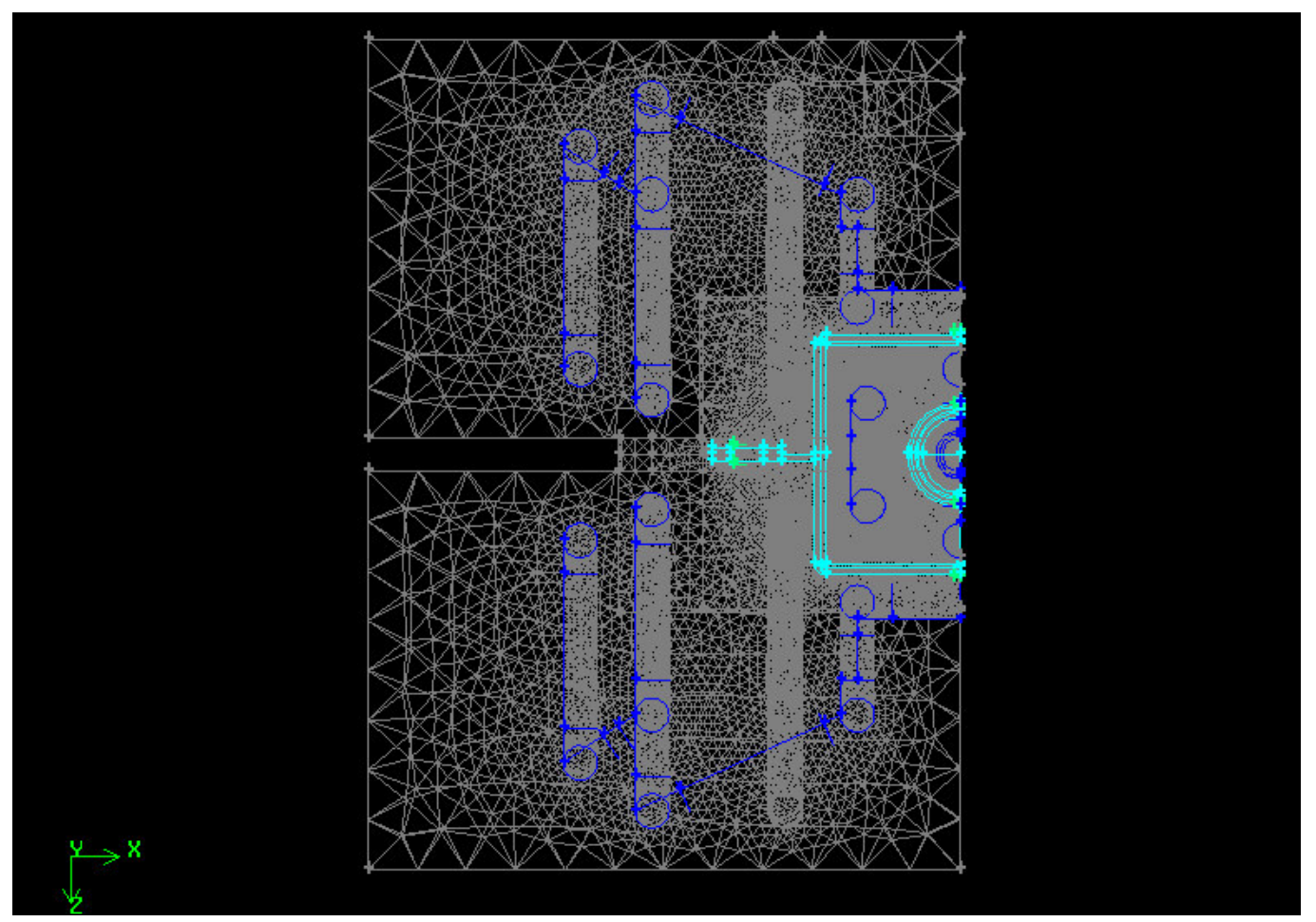

Figure 4: Plan View of Final Mesh 


\subsection{Continuous Cooling Optimisation}

For continuous cooling, the optimum coolant temperatures, obtained computationally using a trial and error approach, were $58^{\circ} \mathrm{C}$ in the fixed and moving zones and $59^{\circ} \mathrm{C}$ in the insert zone channels. Results can be seen in section 3 .

\subsection{Pulsed Cooling Optimisation}

For pulsed cooling, a coolant temperature of $11^{\circ} \mathrm{C}$ was used and a set-point temperature of $53.5^{\circ} \mathrm{C}$ was found to optimise the cooling process for the sensor locations described. The sensor locations were chosen due to their close proximity to both the channels and the surface of the cavity (figures 5 to 7). As the rate of heat transfer through the tool is relatively low due to the low thermal conductivity of the tool steel, positioning the sensors too far from either of these important areas would inevitably result in poor response times. The coolant pulses were initiated for the computational simulations by interrupting the simulation and manually altering the coolant velocities when necessary.

\section{Results and Discussion}

The results presented in this section are for optimised cooling for continuous and pulsed cooling methods. The intermediate results generated in order to obtain optimum conditions are not presented. During all the experiments, data were collected at a number of pressure/temperature transducers located at the surface of the tool cavity, in contact with both the molten polymer and mould tool (see figure 8).

For the purpose of comparison with the computational model, data obtained from the transducers located at the ends of the tensile test bars in both the fixed and moving zones of the tool were used (labelled F and M). Data are only presented for the transducer located in the fixed half of the tool $(F)$ in this paper, as the difference in data for the two zones was negligible, due to similar geometries. Temperatures recorded at the fixed zone transducer were also used to determine cycle times. 
Key:

1 - Fixed Zone Sensor (controls coolant pulses in the fixed zone)

2 - Moving Zone Sensor (controls coolant pulses in the moving zone)

3 - Insert Zone Sensor (controls coolant pulses in the insert zone)

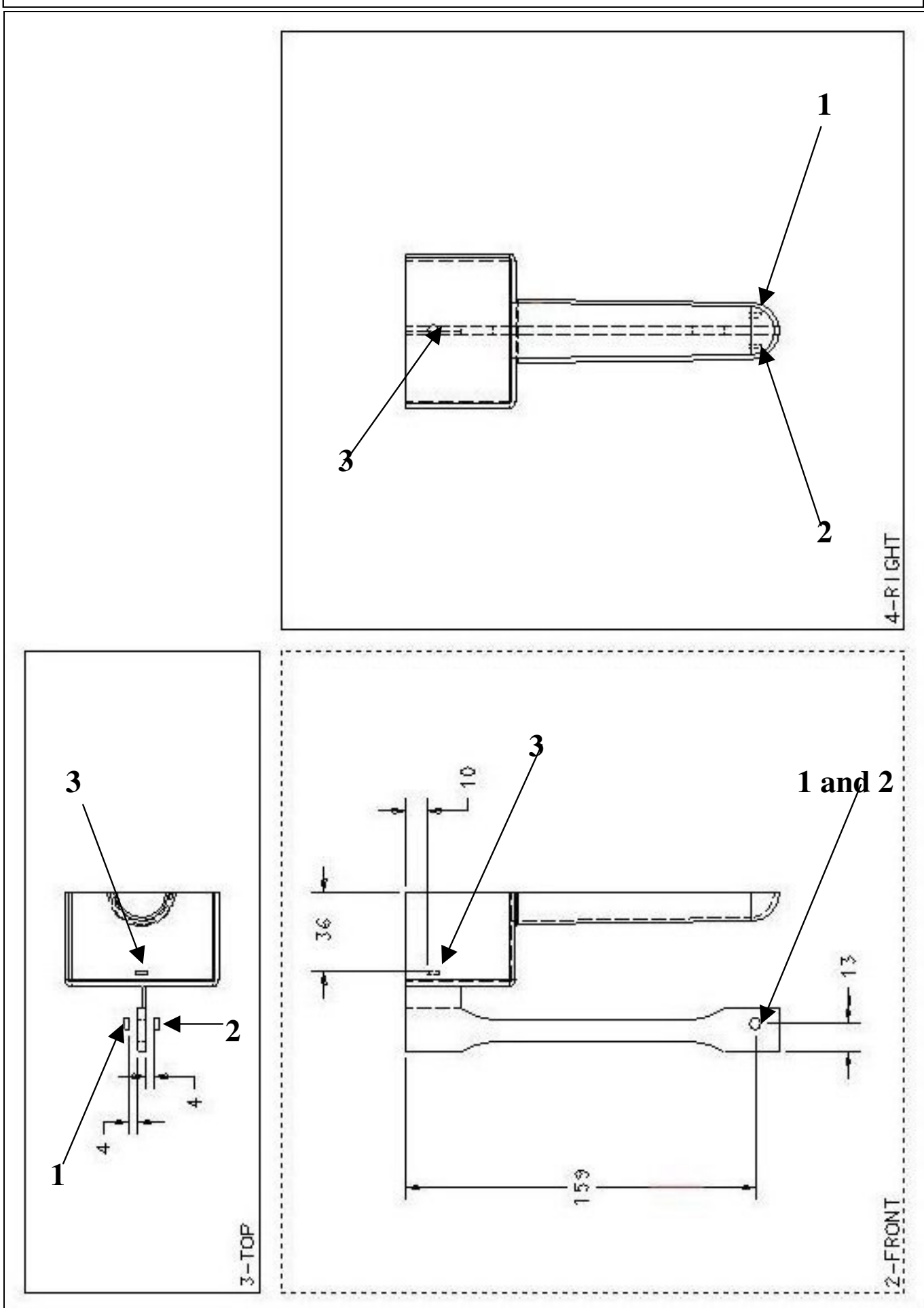

Figure 5: New Zone Sensor Locations for Pulsed Cooling 


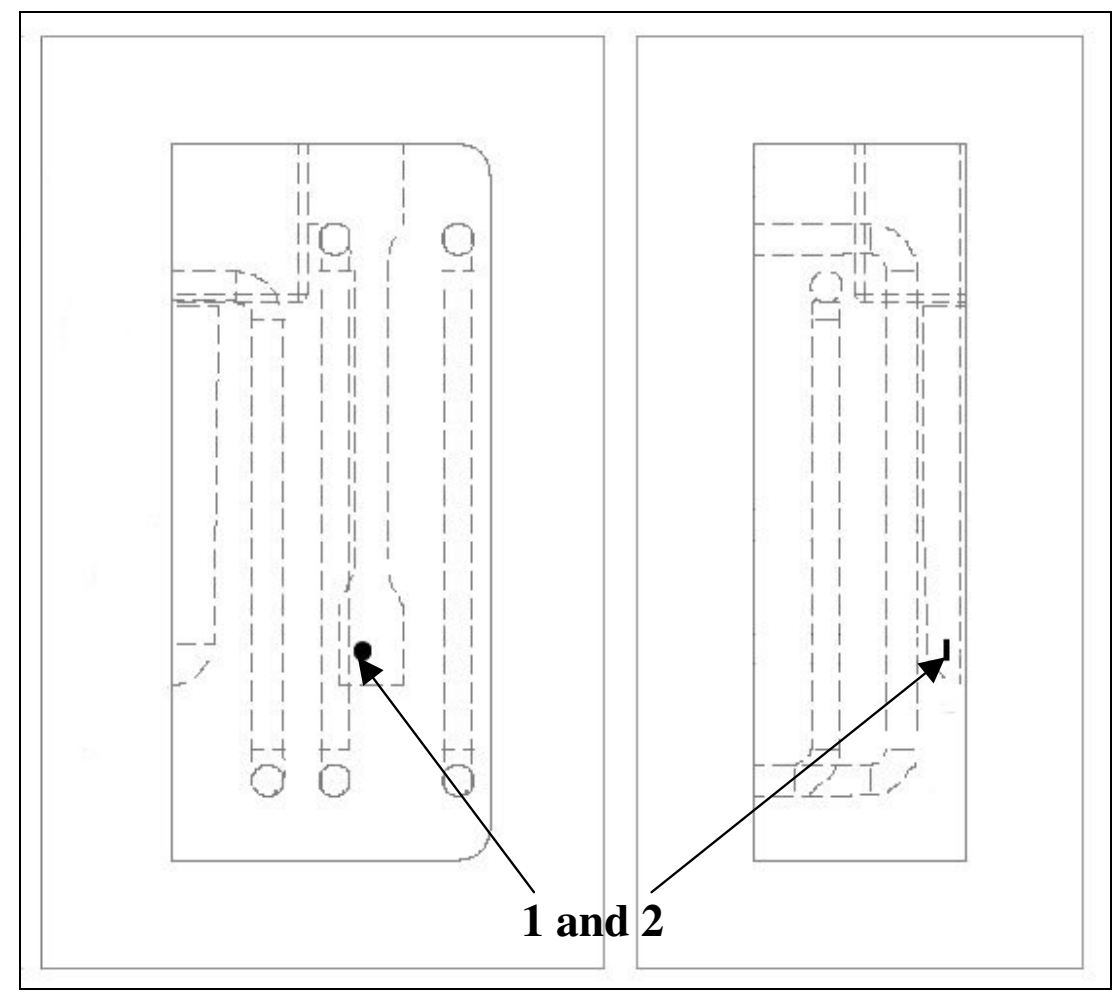

Figure 6: New Zone Sensor Locations for Pulsed Cooling Within the Fixed and Moving Zones of the Tool

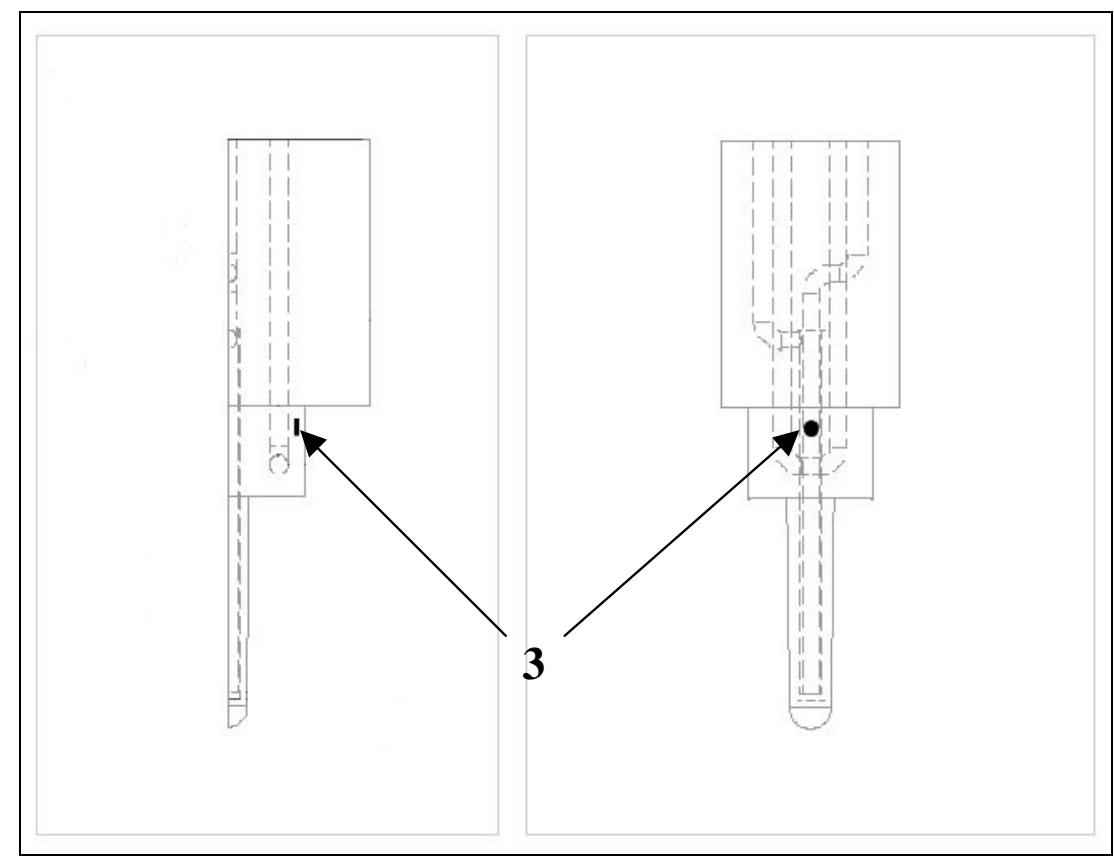

Figure 7: New Zone Sensor Locations for Pulsed Cooling Within the Insert Zone of the Tool 


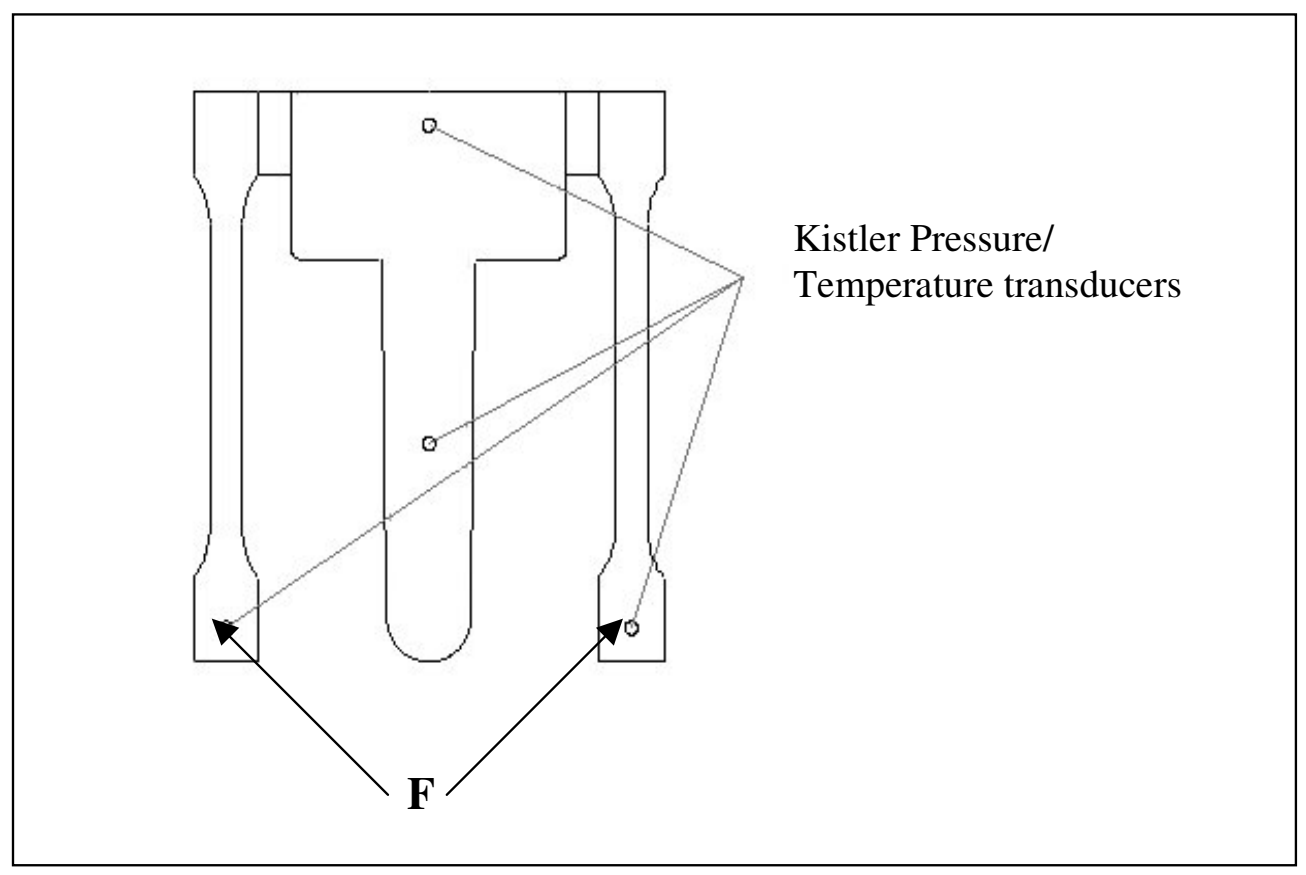

Figure 8: Pressure/Temperature Transducer Locations

\subsection{Continuous Cooling Results}

For continuous cooling, the optimum coolant temperatures, obtained computationally, were $58^{\circ} \mathrm{C}$ in the fixed and moving zones and $59^{\circ} \mathrm{C}$ in the insert zone channels. The higher temperature coolant in the insert zone was due to the close proximity of the fountain to the tool surface. If a colder coolant were used in this zone, overcooling of the insert zone's cavity surface would result.

Figure 9 shows the temperature recorded at transducer $\mathrm{F}$ across 8 complete cycles. This is the number of cycles required to obtain settled data, i.e. the conditions at the start of consecutive cycles are the same. Figure 10 looks more closely at two complete cycles, once steady conditions have been obtained. These results show an optimised cycle time of 58 seconds and hence, an optimised cooling time of 48 seconds.

Figure 11 looks at the minimum temperature on the surface of the cavity in both the fixed and insert zones, across the complete 8 cycles. The aim was to ensure that the 
minimum temperature at the cavity surface was as close to $50^{\circ} \mathrm{C}$ as possible, at the start of each cycle, enabling optimum cooling of the component. Although the temperature in the fixed zone does drop fractionally below this value, the general trend from one cycle to the next is that this value approaches $50^{\circ} \mathrm{C}$ in the fixed zone. It was therefore assumed that the optimum condition was reached.

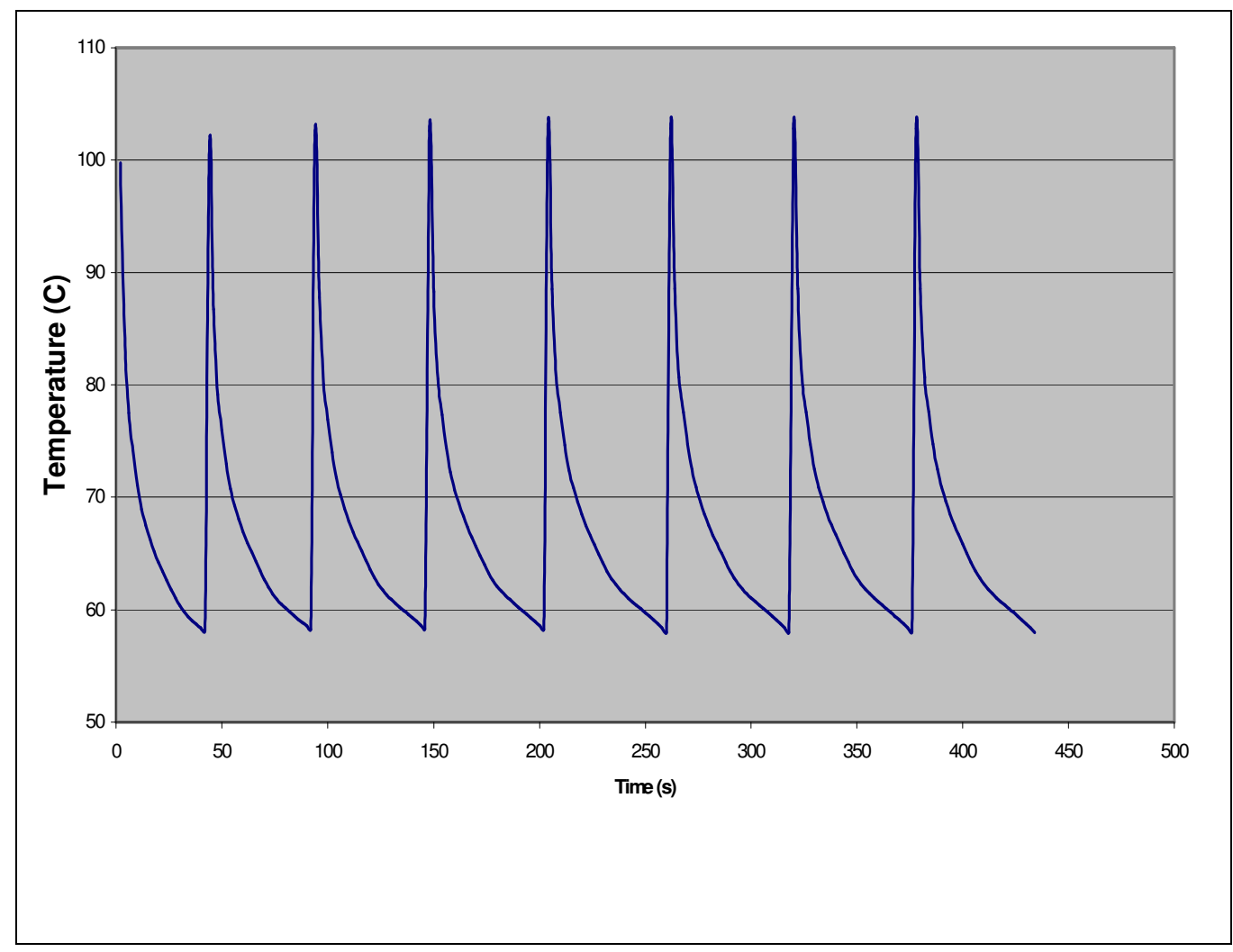

Figure 9: Temperature Measured at Transducer Location F for Optimised Continuous Cooling 


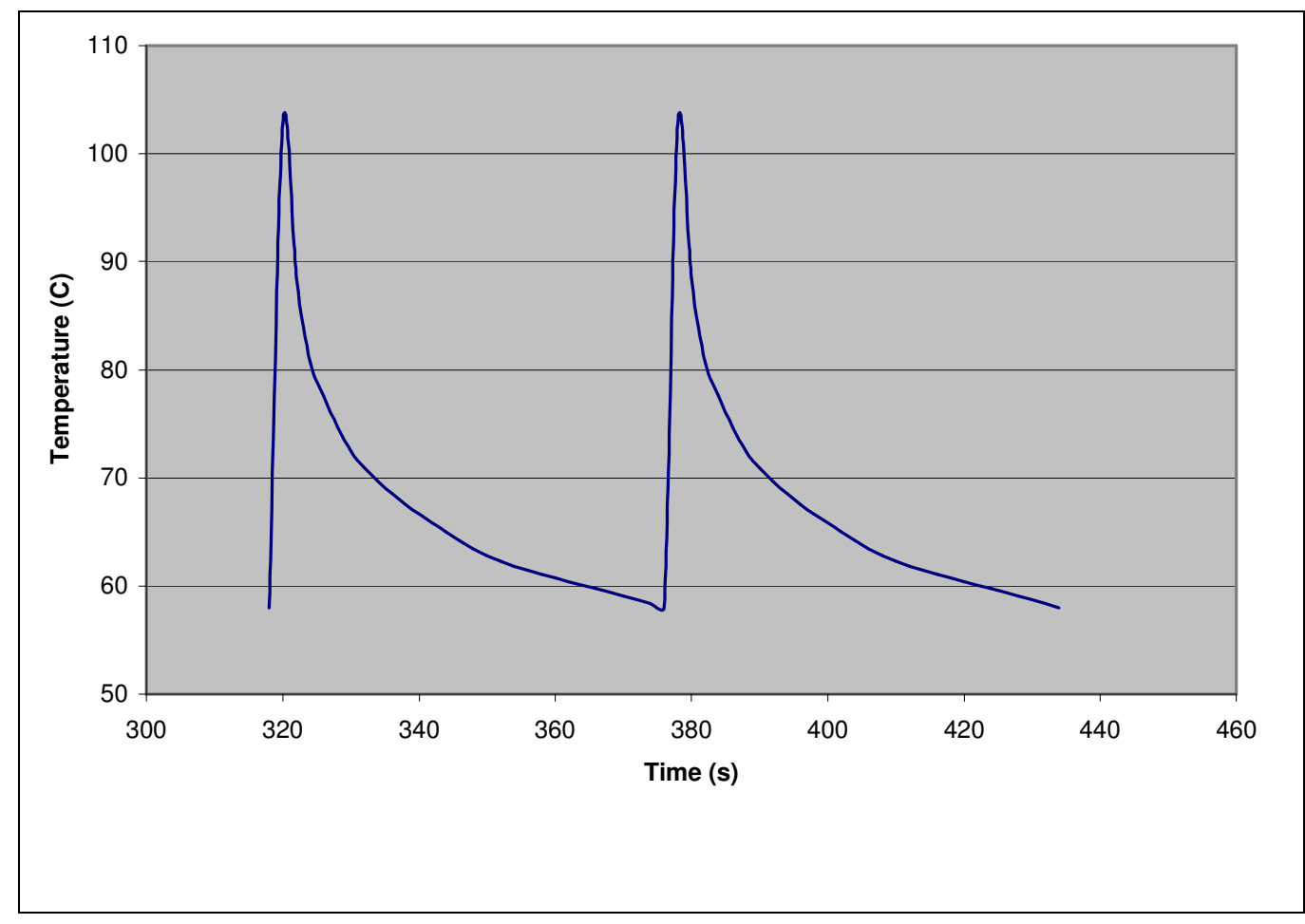

Figure 10: Temperature Measured at Transducer Location F across Two Cycles

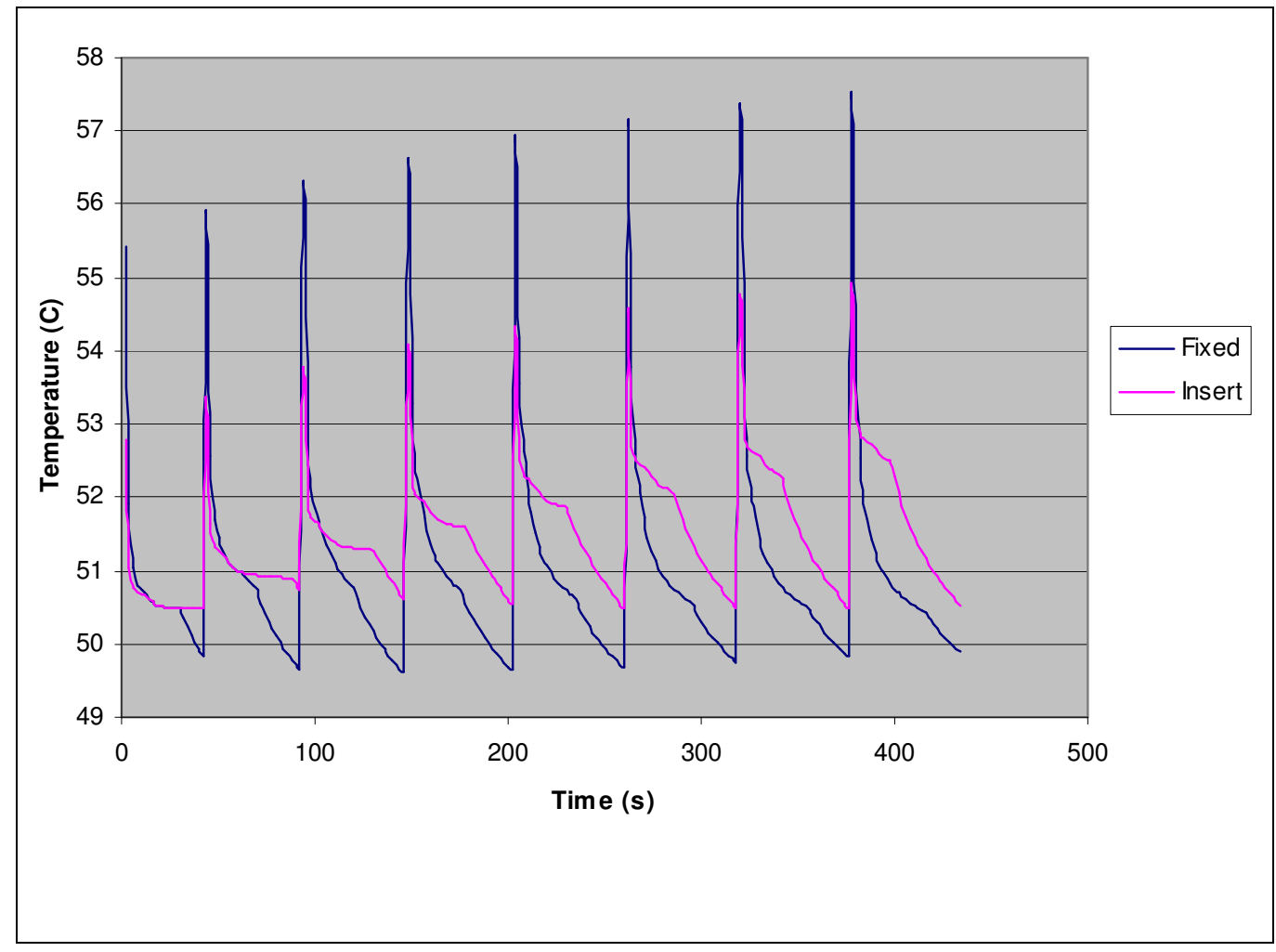

Figure 11: Minimum Temperature at Cavity Surface 
Figure 12 shows the temperature changes at the zone sensor locations, within the body of the fixed and insert zones of the tool. It can be seen that the temperature fluctuates at around 52.25 to $52.75^{\circ} \mathrm{C}$ in both zones. It would therefore follow that to obtain optimised results experimentally, a zone sensor temperature of $52.5^{\circ} \mathrm{C}$ should be maintained, using the coolant temperatures detailed above.

Figures 13 and 14 show that there are temperature variations of around $12^{\circ} \mathrm{C}$ on the surface of the cavity (between $50^{\circ} \mathrm{C}$ and $62^{\circ} \mathrm{C}$ ), prior to the injection of the polymer. As the polymer is injected at $220^{\circ} \mathrm{C}$, this variation is small in comparison and cooling of the component is considered reasonably uniform. The temperature variations are due to channel locations and varying thickness of the component.

Figure 15 shows that the hot fronts from the component and the cold fronts from the channels counteract each other, close to the cavity surface. The temperature profile in the rest of the tool remains relatively unaffected as the process progresses.

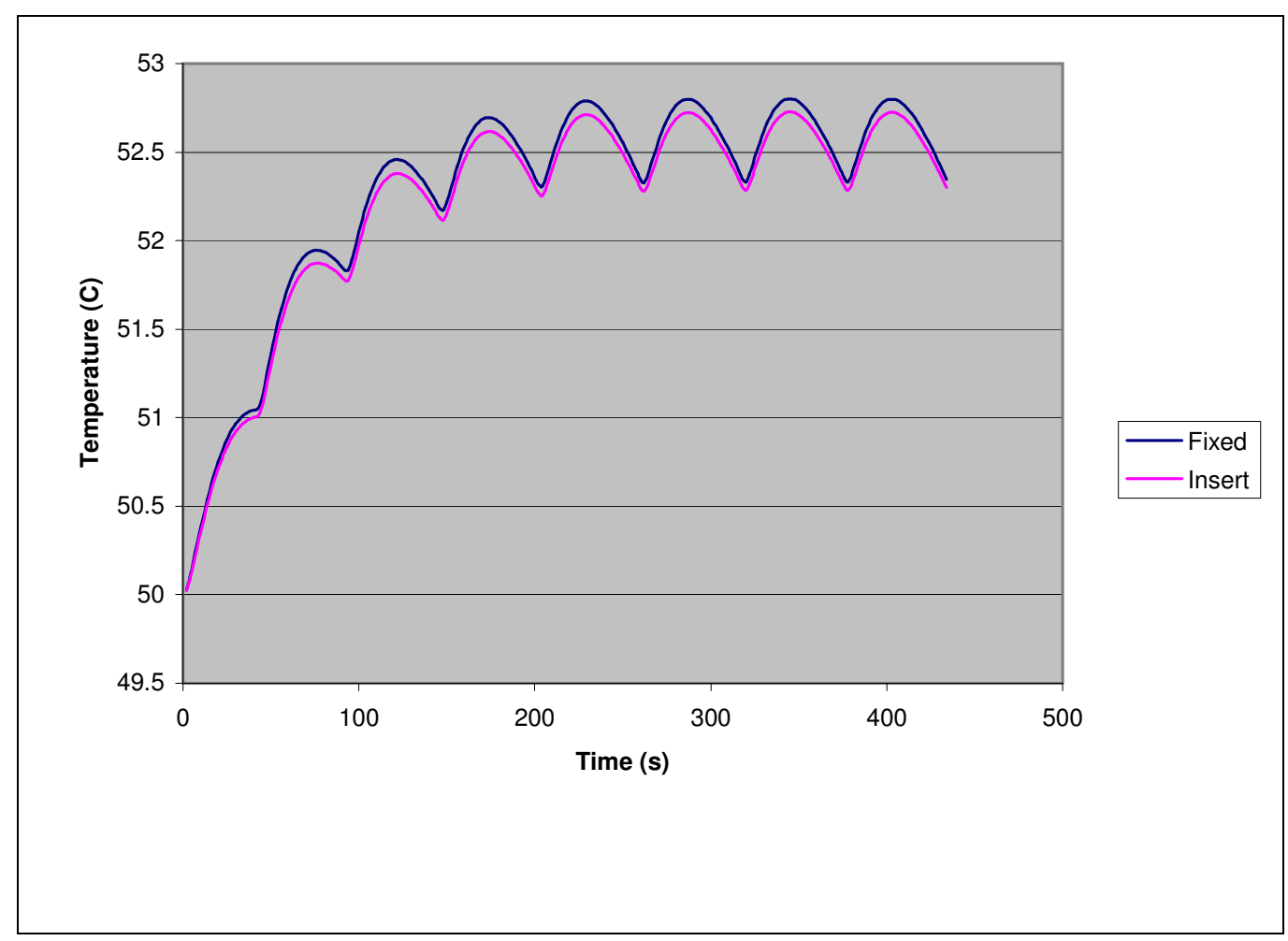

Figure 12: Temperatures Measured at the Zone Sensor Locations 


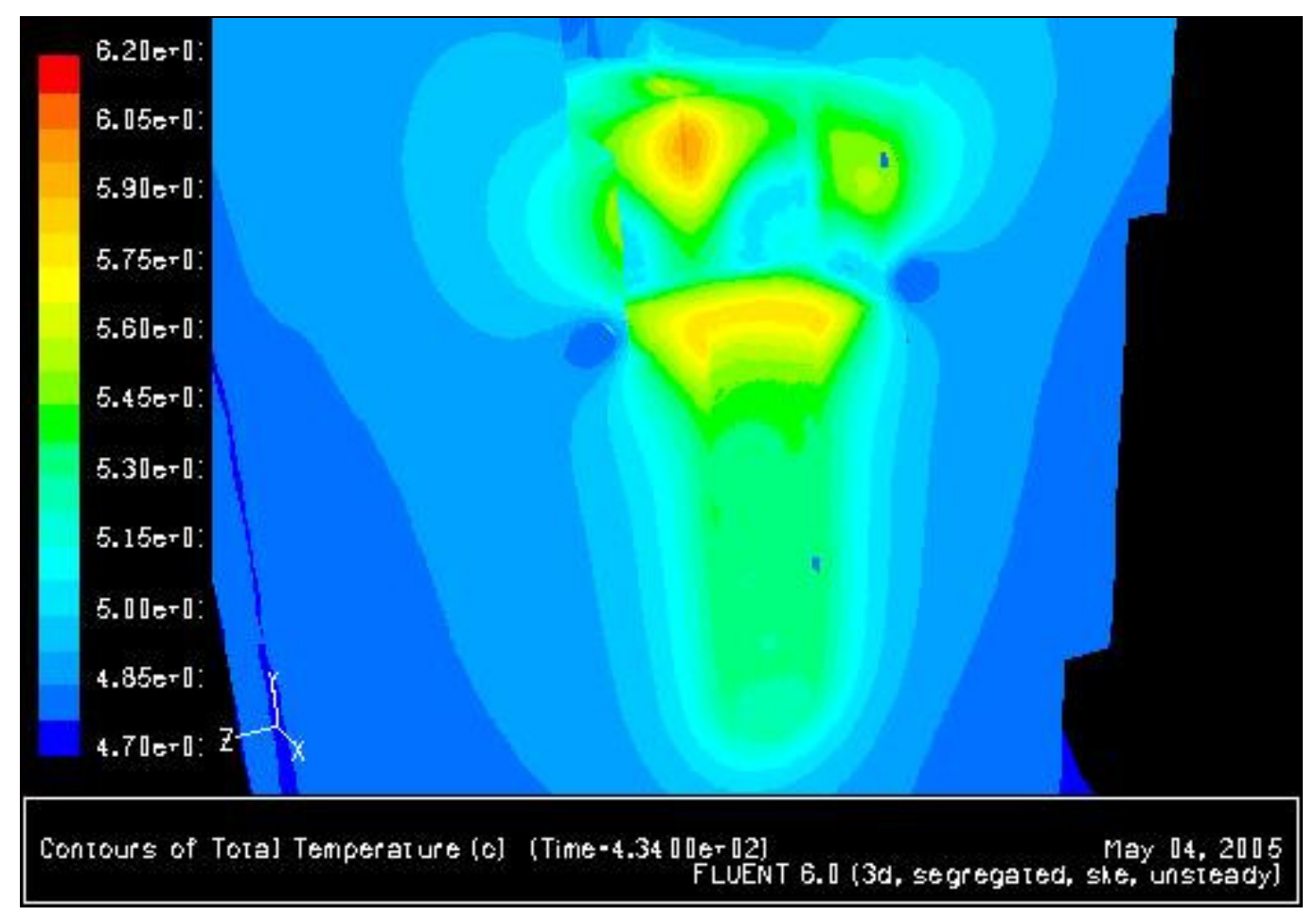

Figure 13: Temperature Contour Plot Showing the Surface of the Cavity in the

\section{Fixed and Moving Zones}

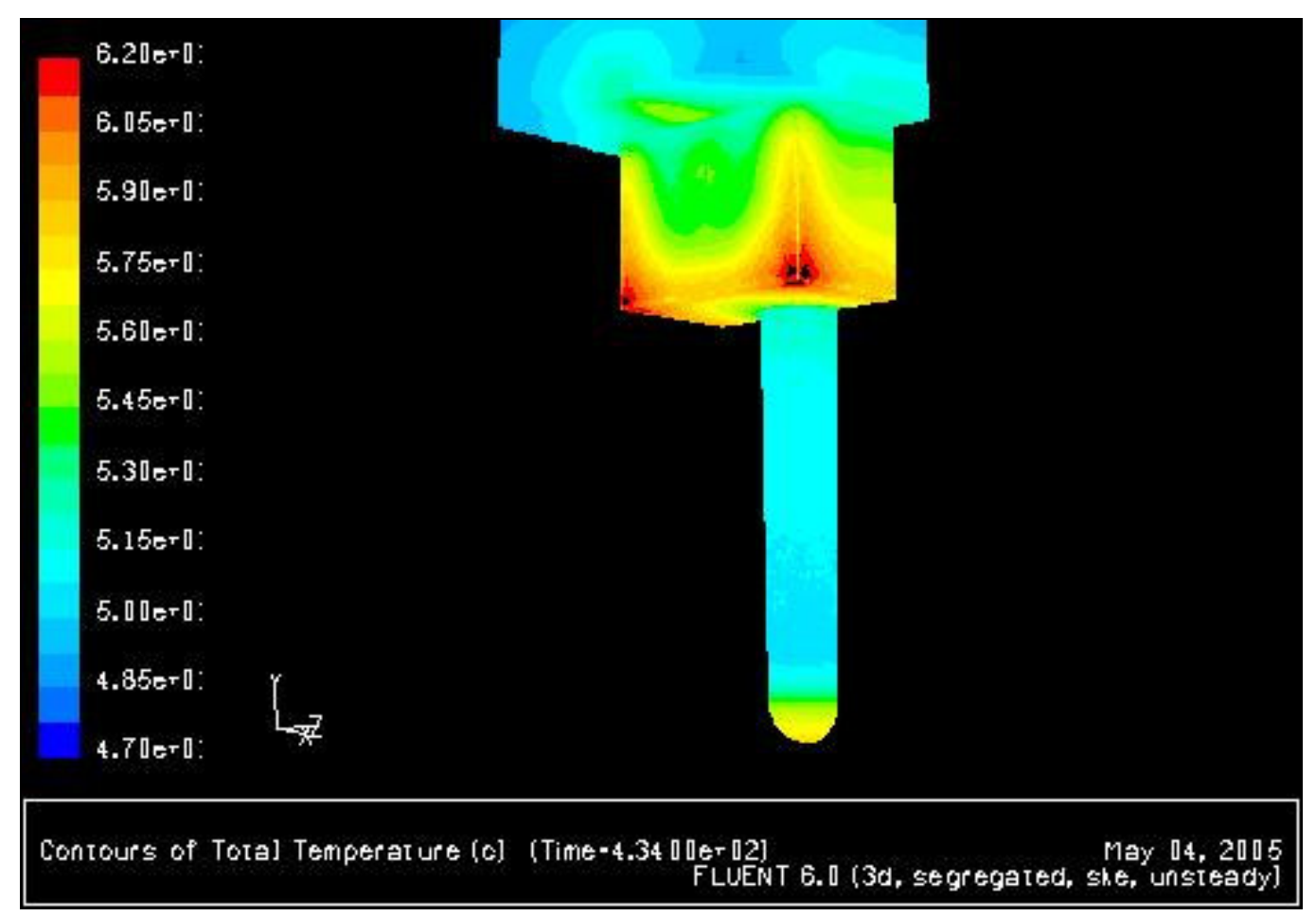

Figure 14: Temperature Contour Plot Showing the Surface of the Insert 


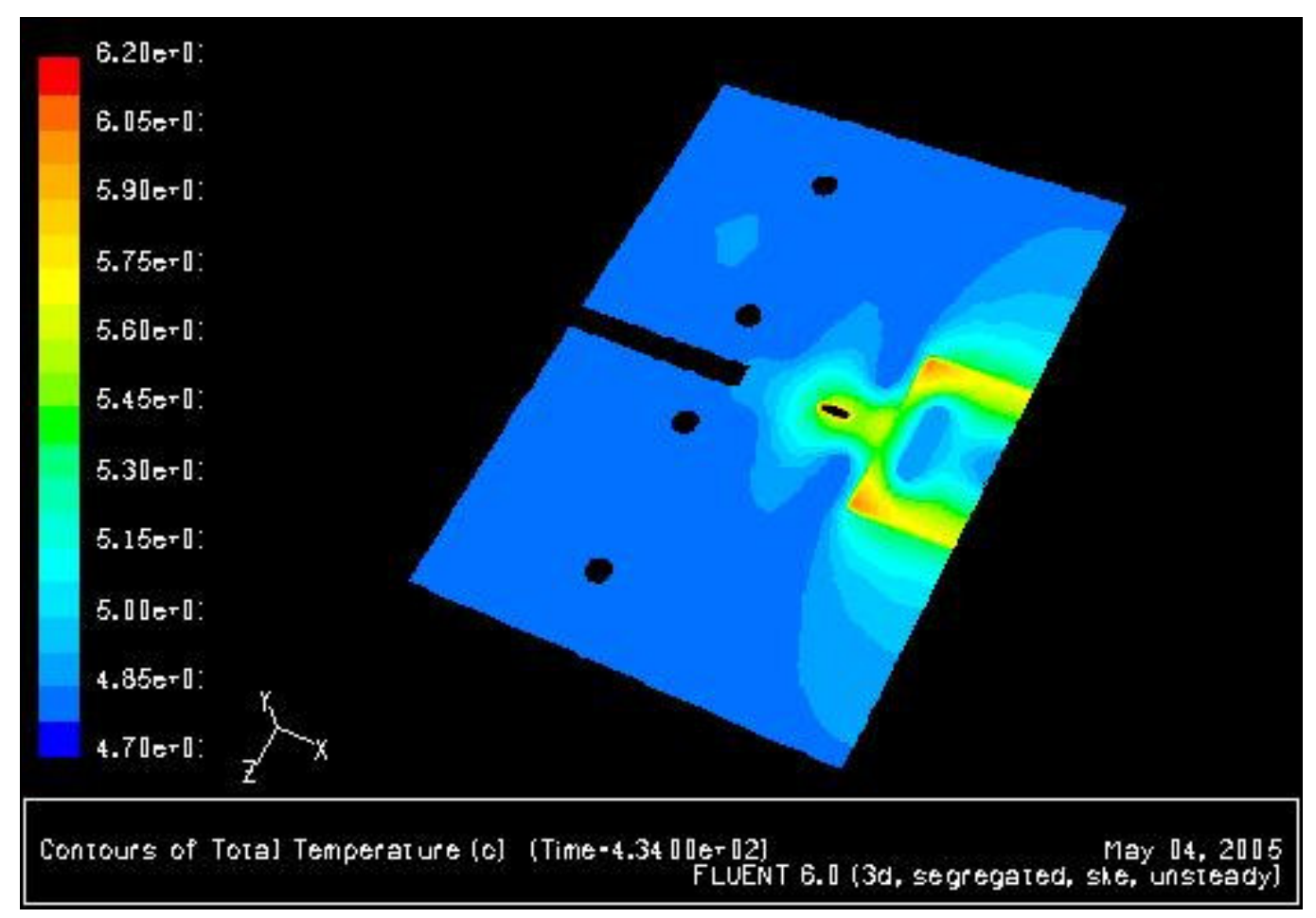

Figure 15: Plane Cut Through the Tool Showing Temperature Contours

\subsection{Pulsed Cooling Results}

The results obtained using an $11^{\circ} \mathrm{C}$ coolant, with a $50^{\circ} \mathrm{C}$ set-point temperature, yielded minimum surface cavity temperatures at approximately $4{ }^{\circ} \mathrm{C}$ lower than the tool running temperature. Results were then obtained using set-point temperatures of $53^{\circ} \mathrm{C}, 53.5^{\circ} \mathrm{C}$ and $54^{\circ} \mathrm{C}$, for comparison. The optimum cycle time was obtained using a set-point temperature of $53.5^{\circ} \mathrm{C}$, in conjunction with the $11^{\circ} \mathrm{C}$ coolant. These results are presented in this section.

Figure 16 displays the data obtained at Transducer location F when sensor 1 was used to control the coolant flow in the fixed zone. From this figure we can see that once the cooling phase is optimised for pulsed cooling, cycle times were recorded at 58 seconds, corresponding to a cooling time of 48 seconds. This is considerably longer than the cycle times for the previous pulsed cooling simulations, because in the earlier simulations, the tool was being overcooled due to the chosen conditions. 


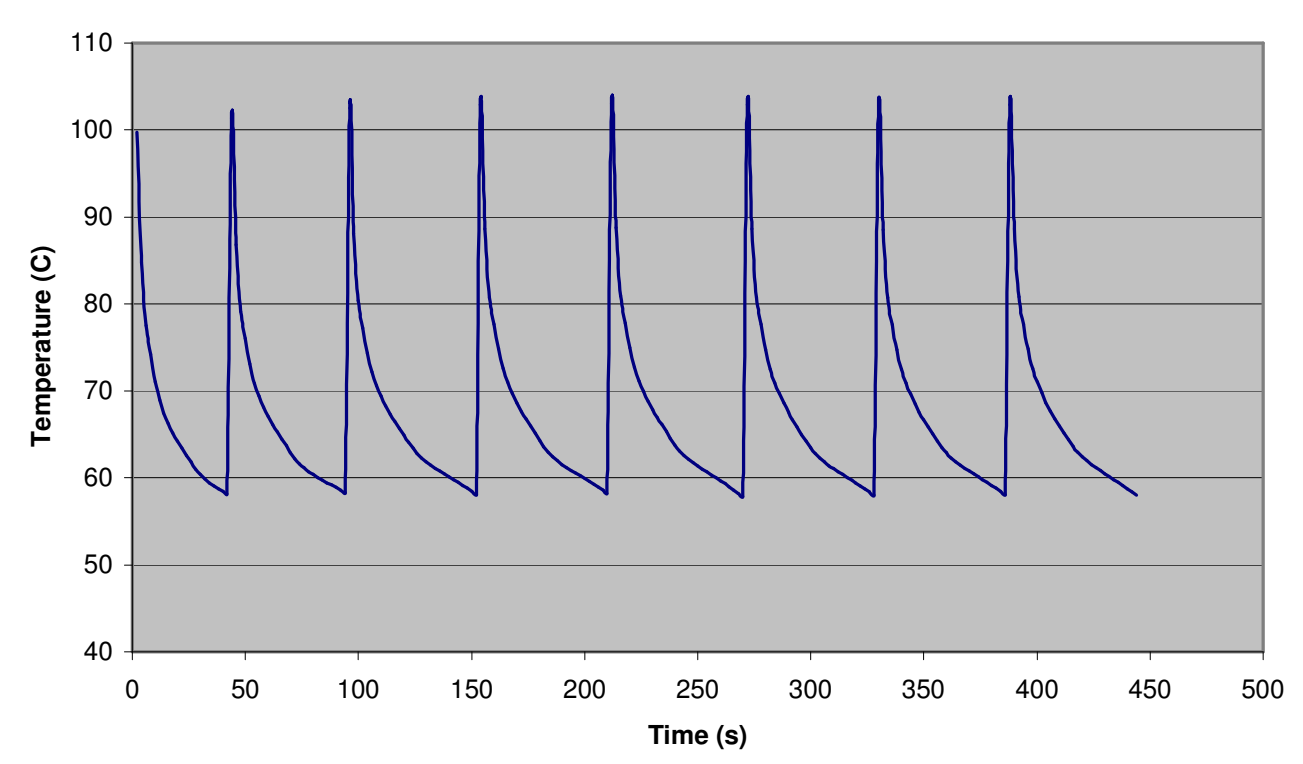

Figure 16: Temperature Measured at Transducer Location F for Pulsed Cooling with a Set-point Temperature of $53.5^{\circ} \mathrm{C}$

When compared with the continuous cooling optimised cycle time (figure 10), it can be seen that the cycle time for both cooling methods is identical. From these results, it can be deduced that there is no obvious benefit to using pulsed cooling over continuous cooling where cycle times are concerned. These results are in agreement with those produced by a much simpler, two-dimensional finite element analysis carried out by Kessler and Pitz [11], who concluded that 'Computer simulations failed to identify significant differences in the cooling times of continuous and pulse-cooled moulds when allowance was made for time-dependent heat transfer in the polymer and the mould. Temperature changes at the mould surface and in the plastic part are almost the same in the two methods'. Similar conclusions were also obtained in the experiments carried out by Bonten [12], who stated that 'The minimum cycle times determined with both types of cooling do not differ significantly'.

Figure 17 shows how short coolant bursts were used in order to maintain the required tool surface temperatures. Although it can be seen that the temperatures at the zone sensors never drops below $50^{\circ} \mathrm{C}$, this is irrelevant, as only temperatures at the surface of the cavity are of interest. 


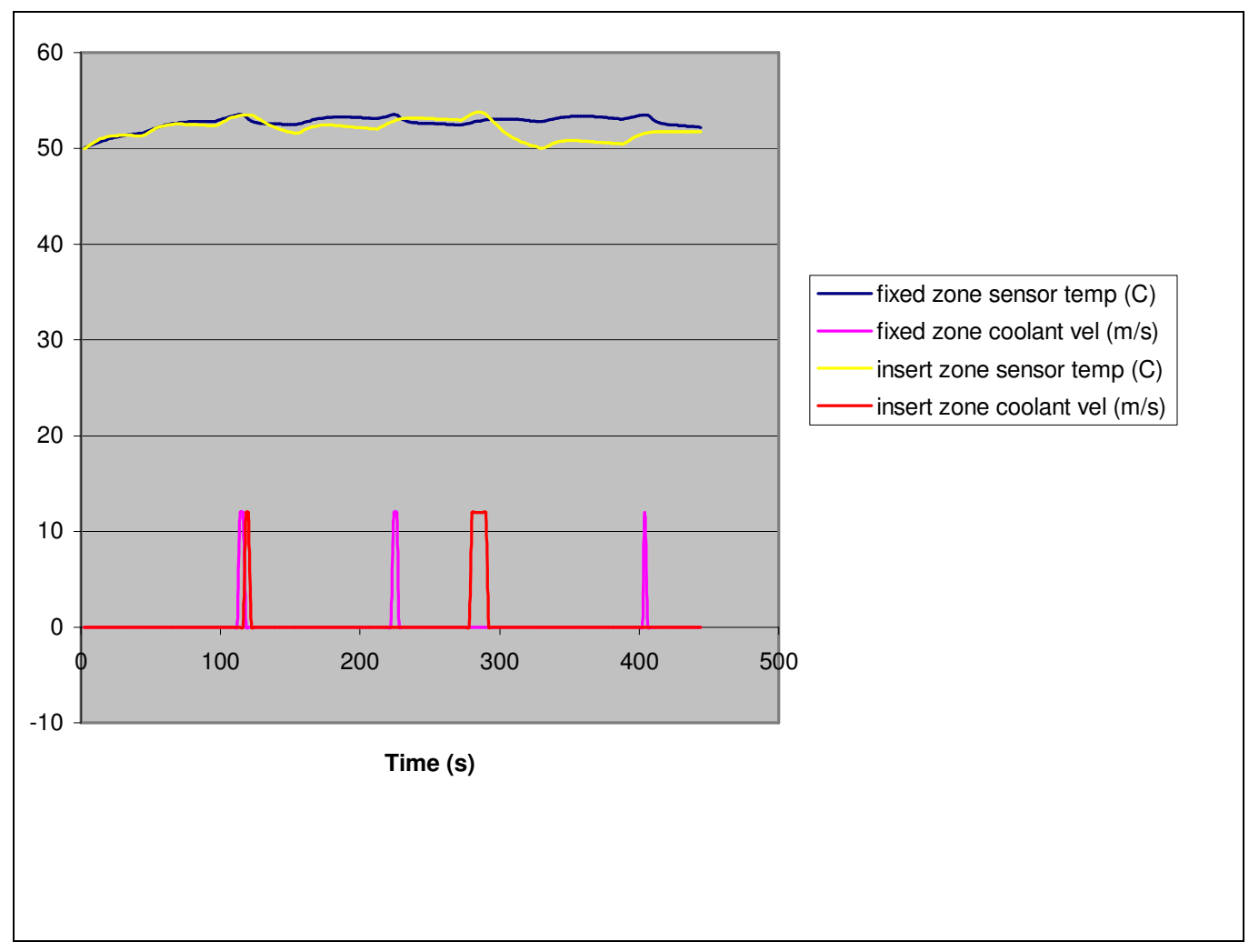

Figure 17: Zone Temperature Values and Coolant Velocity using a Set-point Temperature of $53.5^{\circ} \mathrm{C}$

Figure 18 displays this information. It can be seen that once the system has stabilised, the minimum temperature on the surface of the cavity in each section, was maintained very close to $50^{\circ} \mathrm{C}$. This was the optimised situation, as changing the set point temperature directly affects this condition. Figures 19 to 21 show contour plots at various positions on the tool, enabling comparison with those obtained for continuous cooling and further discussion of the results obtained.

Figures 19 and 20 show that there were temperature variations of approximately $13^{\circ} \mathrm{C}$ on the surface of the cavity, prior to the injection of a consecutive shot. On the insert surface, temperatures ranged from $50^{\circ} \mathrm{C}$ to $63^{\circ} \mathrm{C}$, and on the fixed and moving zones between $50^{\circ} \mathrm{C}$ to $60^{\circ} \mathrm{C}$. Although these values were slightly higher than those obtained using continuous cooling, the difference was negligible when taking into account the temperature of the polymer at injection $\left(220^{\circ} \mathrm{C}\right)$. It can therefore be assumed that there is no benefit to either cooling method, due to this factor. It can be seen for all 
cavity surfaces, that the hot and cold spots were in almost identical positions, regardless of the cooling method adopted (figures 13 and 14 compared with figures 19 and 20).

Comparing figure 21 with figure 15 highlights how the two cooling methods achieve the same result, despite being vastly different in approach. Continuous cooling holds the tool as close to the required temperature as possible, throughout the cycle, whereas pulsed cooling waits until the tool begins to heat up and then sends a short pulse of coolant to remove the same quantity of heat in the same time. Continuous coolant flow suppresses the hot fronts generated by hot polymer, whereas pulsed cooling allows the hot front to propagate, before neutralising it with a cold front.

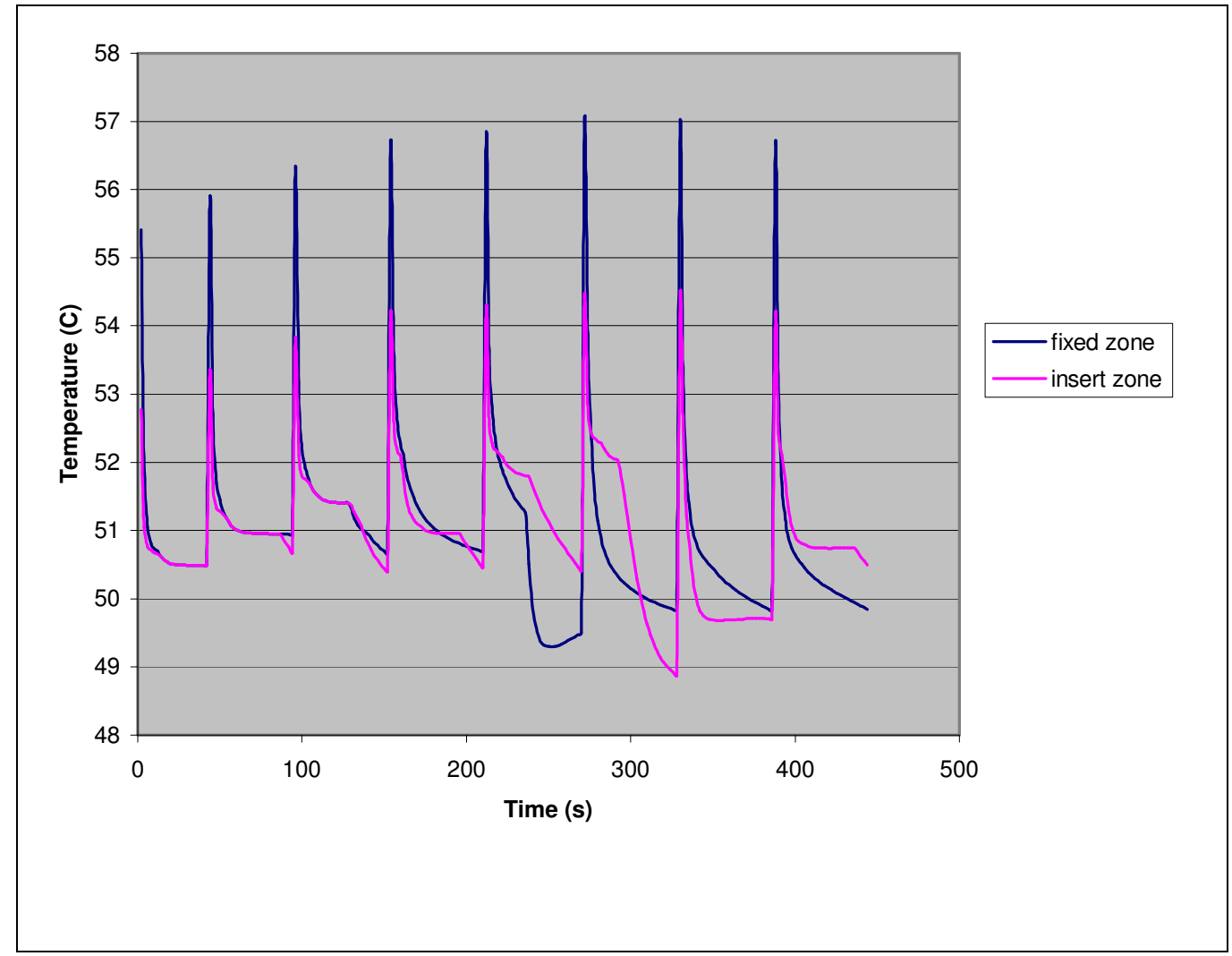

Figure 18: Minimum Cavity Surface Temperature with a Set-point Temperature of $53.5^{\circ} \mathrm{C}$ 


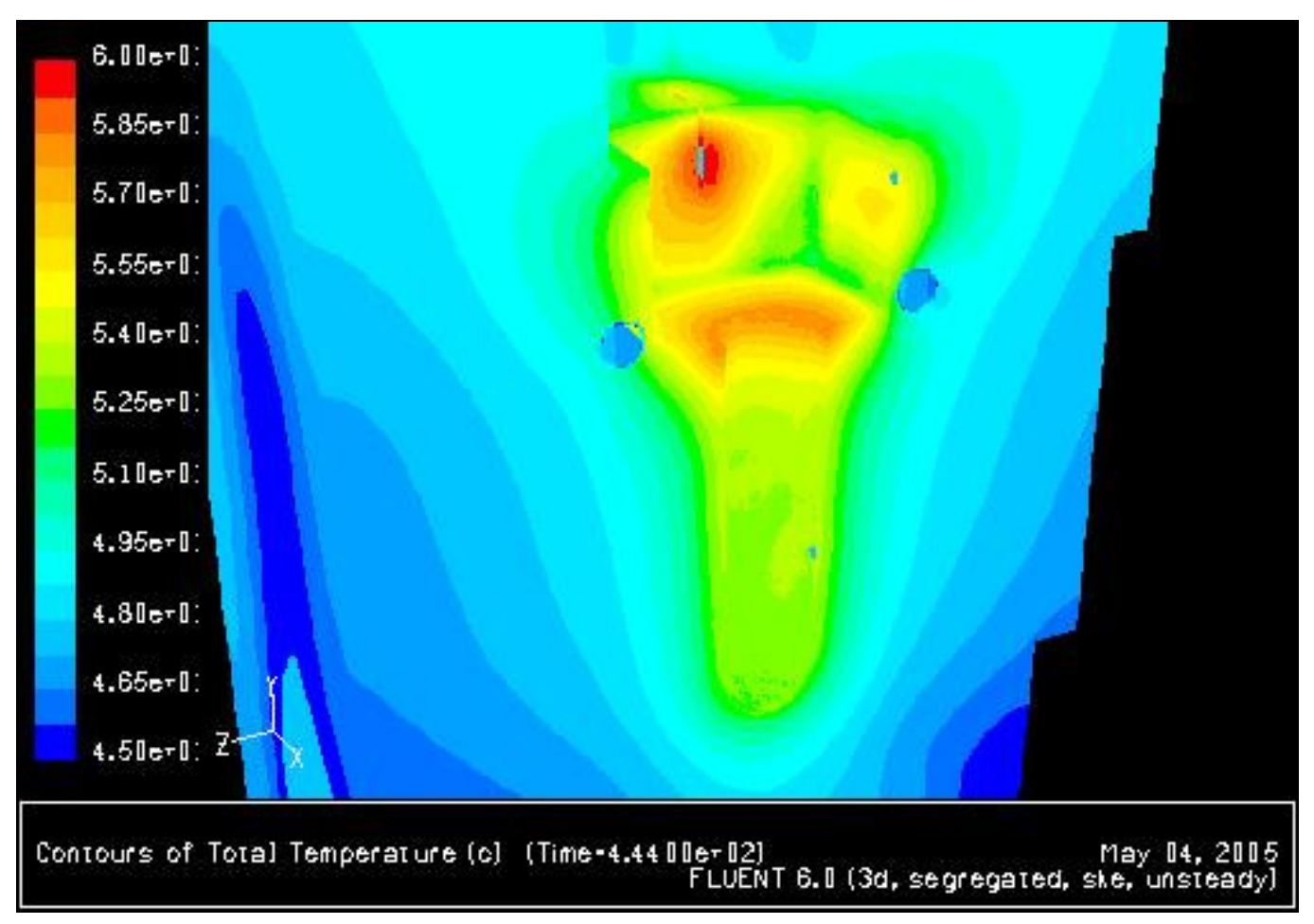

Figure 19: Temperature Contour Plot Showing the Surface of the Cavity in the Fixed and Moving Zones

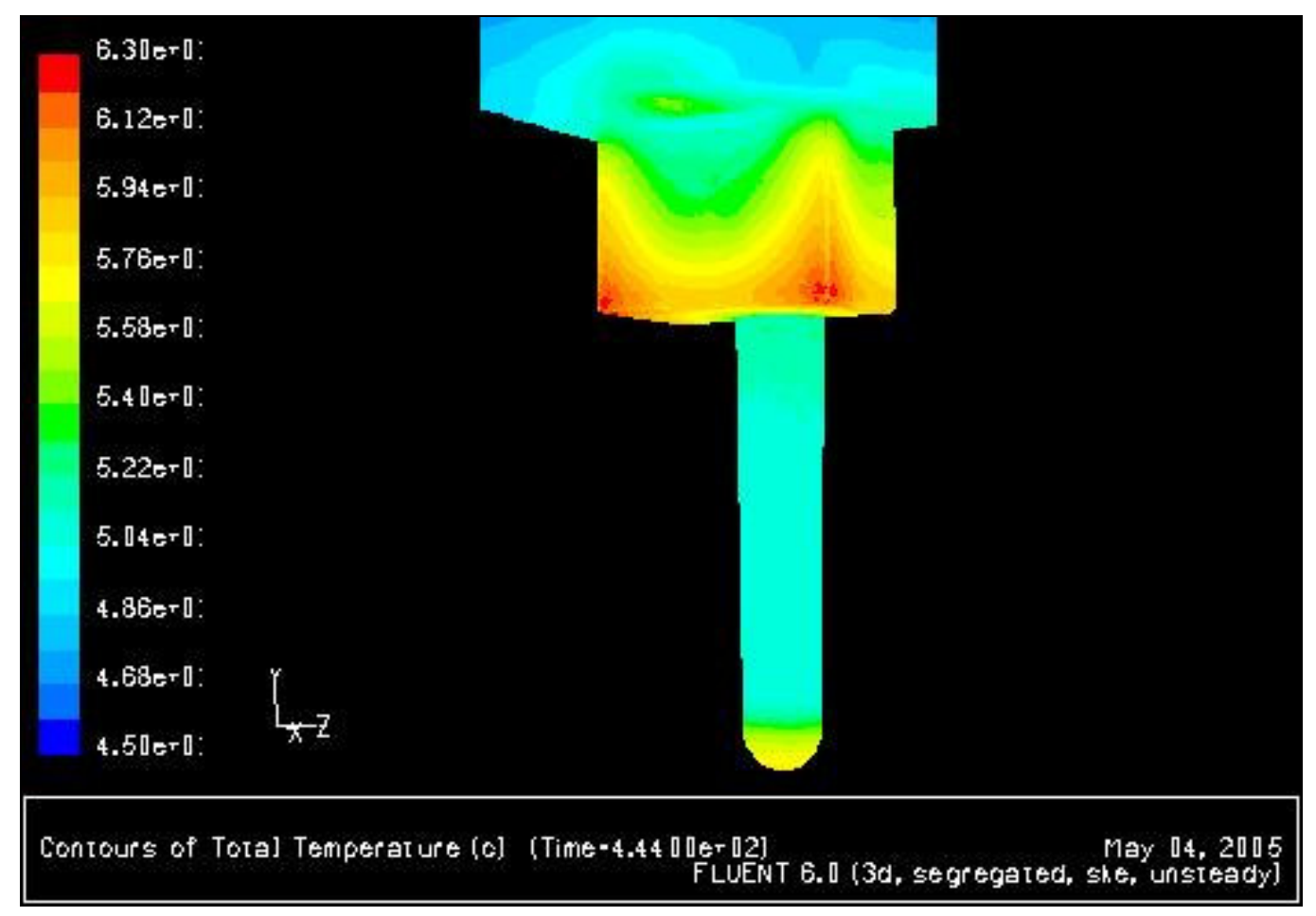

Figure 20: Temperature Contour Plot Showing the Surface of the Insert 


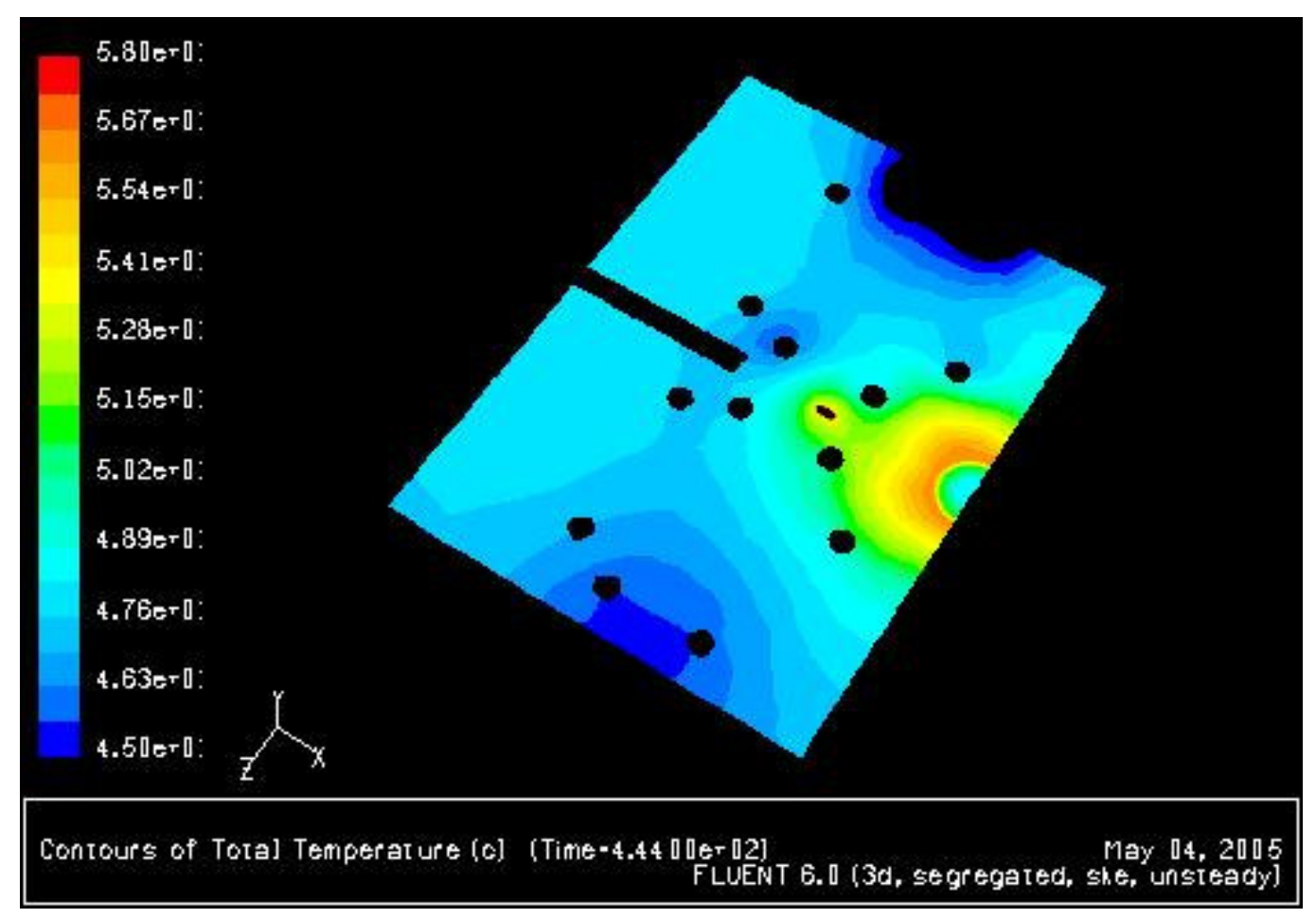

Figure 21: Plane Cut Through the Tool Showing Temperature Contours

\section{Conclusions}

One benefit of the computational model was the ability to monitor temperature values and to view temperature contour plots for any chosen face. This ensured that the surface cavity temperature was maintained during optimisation and also allowed to locate the coldest areas on the surface, prior to injection of a consecutive shot. By taking a cross sectional cut through the tool, the hot and cold fronts were analysed as they propagated through the tool. None of this was possible using the experimental setup, without the use of expensive infrared thermal imaging technology.

It has been demonstrated that pulsed cooling does not appear to offer reductions in cooling time, when compared with continuous cooling. In this regard, the optimised continuous cooling data has been directly compared with the optimised pulsed cooling data for the chosen tool running temperature of $50^{\circ} \mathrm{C}$ and the cooling times have been shown to be identical (48 seconds). These results are in agreement with those presented by Kessler and Pitz [11] and Bonten [12]. It has been reported, however, that pulsed cooling provides a number of other advantages [4-6, 12], such as cost- 
effective multi-zone temperature control of complex components with different control zones, lower capital costs, smaller space requirement, lower use of cooling medium, reduced power requirement and lower maintenance costs, which have not been considered in the present study.

\section{Acknowledgments}

The work described in this paper forms part of the Enhanced Polymer Processing programme funded by the EPSRC, in collaboration with the University of Bradford and Queen's University Belfast. The authors would like to acknowledge the support from REPS Ltd.

\section{References}

[1] CITO Products Inc, Cooling System Categories, [http://www.pulsecooling.com/cooling\%20systems.htm], accessed15/11/03

[2] P. Mapleston, Pulse cooling yields - Cost and operational benefits, Modern Plastics, Vol. 8, S. 30, 2002.

[3] www.reps.co.uk, 11 Good Reasons Why You Should Change to REPS Cyclical Mould Temperature Controllers, [http://fp.repsuk.plus.com/articles/whyreps.htm], (accessed 8/10/03)

[4] B.A. McCalla, P.S. Allan, P.R. Hornsby, A.G. Smith, L.C Wrobel, A.L. Kelly and P.D. Coates, Evaluation of pulsed cooling in injection mould tools, Polymer Process Engineering 03, pp. 52-71, Bradford, UK, 2003

[5] A.L. Kelly, M. Woodhead, P.D. Coates, P.S. Allan and R.F. Evans, Effect of pulsed cooling on the injection moulding process, ANTEC 2002, Society of Plastics Engineers, 2002

[6] T.R. Carl and J.L. Burrow, Comparison of energy consumption with two methods of injection mould cooling, ANTEC 2002, Society of Plastics Engineers, 2002

[7] A.G. Smith, A Computational Model for the Cooling Phase of Injection Moulding, PhD Thesis, Brunel University, Uxbridge, UK, 2006 
[8] www.basell.com, Product Data and Technical Information - Polypropylene, homopolymer SM6100, [http://www.basell.com/portal/site/basell/index.jsp?epicontent $=$ GENERIC\&range 2 from $=\&$ grade $=$ sm6100 \&brochure_start_doc $=0 \&$ epi _menuItemID=483732eb145b68bdf5305285a0f034a0], accessed 05/12/04

[9] Engineering.com, Typical Values of Convection Heat Transfer Coefficients, [http://www.engineering.com/content/ContentDisplay?contentId=41005014], accessed 17/03/2004

[10] Fluent 6.0 User Guide, Fluent Inc., 2003

[11] C. Bonten, Search for sense, Kunststoffe, Vol. 93, pp. 80-83, 2003

[12] A. Kessler and H.J. Pitz, Shorter cycle times with pulsed cooling?, Kunststoffe, Vol. 92, pp. 52-56, 2002 